\title{
An Observational Study of Magnetic Resonance Imaging Evaluation of Encephalitis
}

\author{
Dr BS Salooja \\ Associate Professor Department Of Radiodiagnosis, Universal College Of Medical Sciences And TH, \\ Bhairahawa, Nepal
}

\begin{abstract}
Objective: To evaluate the role of magnetic resonance imaging in encephalitis cases.
Methods: The present descriptive study was carried out using a prospective study design. Age group included in the study was above 15 years. Patients clinically presenting with symptoms and signs suggestive of encephalitis were included in the study. MRI scan was performed in all patients.

Results: The mean $( \pm S D)$ age of the patients was $37.03( \pm 21.86)$ years. Thalami involvement was observed most commonly which is seen in 45\% (18) case followed by Temporal lobe involvement in $42.5 \%$ (17), then Frontal lobe and Basal ganglia in 35\%(14),Mid brain in 32.5\%(13),Cerebellum in 30\%(12), Pons and Medulla both in 27.5\%(11),Parietal lobe in 17.5\%(7), Occipital lobe 20\%(8).Hence most common sites of brain involvement were thalami, temporal lobe, frontal lobe and basal ganglia.

Conclusion: Suggestive MRI findings are present in some etiologies of viral encephalitis such as Herpes simplex encephalitis, JE, enterovirus encephalitis MRI may show non-specific features of viral encephalitis such as cortical hyperintensities and cerebral edema. MRI is also useful for diagnosing alternative etiologies such as Acute disseminated encephalomyelitis, and antibodyassociated encephalopathies.
\end{abstract}

Keywords: Encephalitis, Magnetic resonance imaging, Etiologies

\section{Introduction}

Encephalitis is the presence of an inflammatory process in the brain parenchyma associated with clinical evidence of brain dysfunction. Encephalitis by the herpes simplex virus is the leading cause of most severe cases in all the ages including newborns (Beig, 2010). It is mediated via metabolic processes and can be caused by intoxications, drugs, systemic organ dysfunction (e.g. liver, pancreas) or systemic infection that spares the brain. (Steiner et al, 2005).

Acute encephalitis syndrome (AES) is a clinical condition caused by infection with Japanese encephalitis virus (JEV) or other infectious and noninfectious causes. A confirmed etiology is generally not required for the clinical management of AES. Thus, surveillance for JEV infection in India has focused on identifying AES cases rather than JE cases; this approach is more feasible given the limitations of public health resources (Hills et al, 2009).

Magnetic resonance imaging (MRI) is more sensitive and specific than CT for the evaluation of viral encephalitis' (Dun et al., 1986; Schroth et al., 1987; Dale et al., 2000; Marchbank et al., 2000). The advantages of MRI include its multiplanar imaging capability, improved soft tissue contrast, and high anatomical resolution. It is imaging technique of choice in evaluation of encephalitis. It allows earlier detection and treatment of inflammatory processes. MRI also provides valuable information for patient follow up.

The present study was designed to evaluate the role of magnetic resonance imaging in encephalitis cases.

\section{Material And Methods}

The present descriptive study was carried out using a prospective study design. Age group included in the study was above 15 years. Patients clinically presenting with symptoms and signs suggestive of encephalitis were included in the study. Patients confirmed to have diagnosis other than encephalitis were excluded from the study. All the patients clinically suspected to have encephalitis were invited to participate in the study.

Informed consent was obtained from all the patients/their guardians willing to participate in the study. After obtaining the informed consent and ensuring that they met the inclusion criteria and not falling into the domain of exclusion criteria were enrolled as the study subjects. From all the patients consenting to participate in the study, demographic information, detailed medical history, details of current illness were recorded. A thorough clinical examination was carried out. MRI scan was performed in all patients.

\section{Results}

The mean $( \pm \mathrm{SD})$ age of the patients was $37.03( \pm 21.86)$ years. One fourth of patients were in between $12-20$ years $(25 \%)$ of age group followed by age group $41-50$ years (22.5\%), than $>50$ of year of age group (20\%), 21-30 yr group (17.5\%) and 31-40 years group (15\%). More than half $(55 \%)$ of the patients were males 
and females cases were $45 \%$ (Table-1). The most common presenting symptom in encephalitis cases was fever which is seen in $(92.5 \%)$ cases, followed by seizure $(87.5 \%)$ altered sensorium $(85 \%)$, Neck rigidity $(70 \%)$ and headache $(67.5 \%)$ (Table-2).

Thalami involvement was observed most commonly which is seen in $45 \%$ (18) case followed by Temporal lobe involvement in 42.5\%( 17), then Frontal lobe and Basal ganglia in 35\%(14), Mid brain in $32.5 \%(13)$,Cerebellum in 30\%(12),Pons and Medulla both in 27.5\%(11),Parietal lobe in 17.5\%(7), Occipital lobe $20 \%(8)$.Hence most common sites of brain involvement were thalami, temporal lobe, frontal lobe and basal ganglia (Table-3).Out of the total 40 case encephalitis cases, $55 \%(22)$ was JE (Thalami, Basal ganglia and Brain stem involvement is seen), $45 \%$ (18) was HSV (Temporal lobe, Insular cortex, Frontal lobe involvement seen (Table-4).

\section{Discussion}

The present study was conducted with the objective to evaluate the role of magnetic resonance imaging in encephalitis cases. A total of 65 clinically suspected cases were recruited in the study. Out of these, 40 cases were diagnosed encephalitis on MRI. The CSF routine examination was done in all diagnosed cases of encephalitis on MRI.

Encephalitis is associated with severe illness, appreciable mortality rates, and high health care costs (Khetsuriani et al, 2002), but its epidemiology remains poorly understood (Granerod et al, 2010). The etiology of encephalitis should be diagnosed early as increasing number of viruses have been found to cause encephalitis in humans (Whitley and Gnann, 2002; Warrell and Warrell, 2004; Warrell and Warrell, 2005). Although specific therapy is limited to only few viral agents, correct diagnosis with supportive and symptomatic treatment are mandatory to ensure best prognosis (Chaudhari and Kennedy, 2002; Redington and Tyler, 2002).

In the present study, the percentage of encephalitis cases is higher among the age group of 12-20 years and after 40 years with higher incidence among males, which is consistent with previous studies (Lee et al, 2003; Cizman and Jazbec, 1993; Nicolosi et al, 1986) which also illustrated these age groups more susceptible to viral encephalitis. Hyporesponsiveness of the immune system in early life and later immunosenescence render these age groups more susceptible to infection, to reactivation of latent infection, or development of encephalitis once infected (Tregoning and Schwarze, 2010).

Clinical features of encephalitis comprise an incubation period of 1-4 weeks (average, 2 weeks), then a prodrome of 2-5 days that usually includes fever (often $>40^{\circ} \mathrm{C}$ ) and headache (Cordova et al, 2000). Other prodromal features may include nausea, vomiting, diarrhoea, macular rash and cough (Burrow et al, 1998). Neurological features occur early and may include lethargy, irritability, confusion and Seizures almost invariably occur in children, and may also occur in adults (Burrow et al, 1998) ${ }^{30}$ In the present study also fever, headache, seizures, altered sensorium and neck rigidity was the most common symptoms find in encephalitis cases which were common among children and adults also.

In the present study, temporal lobe involvement was present in $42.5 \%$ of patients; frontal lobe in $35 \%$, parietal lobe in $17 \%$ and occipital lobe in $10 \%$. The findings of this study is consistent with previous study of 18 patient by Salih et al (2009) which showed s unilateral or bilateral hypointensity in the temporal lobes in eight patient $(44.4 \%)$, frontal lobe in six patient $(35 \%$,) parietal lobe in three patient $(16.6$,$) and occipital lobes$ in two patient $(11.1 \%)$.

In this study, thalamic involvement was present in $45 \%$ of cases and basal ganglia involvement was present in $35 \%$ of cases, midbrain involvement was present in $32.5 \%$, Pons \& medulla involvement was present in $27.5 \%$ and cerebellum involvement was present in $30 \%$ of cases. The result of this study is consistent with study by Kalita and Misra (2004) of 31 cases which showed lesion in the thalami in $41.9 \%$ cases, basal ganglia in $35.5 \%$ cases, midbrain in $29 \%$ cases, Pons in $25.8 \%$ cases, cerebellum and cerebral cortex in $19.4 \%$ cases each.

In the present study, out of the total 40 cases of encephalitis, $55 \%$ (22) were JE (Thalami, basal ganglia and brain stem involvement was seen). JE was first recognized via a serological survey in the 1950s in India (Smithburn et al, 1954). The first JE outbreak was reported in West Bengal in 1973, followed by reports in southern, eastern, and western states (Chakravarty et al, 154). JE was first reported in Uttar Pradesh, the main JE epidemic area in the northern part of India in 1978 (Mathur et al, 1982) after that, a severe outbreak of JE occurred with 5,700 cases and 1,315 deaths in Uttar Pradesh state in 2005 (Kumar et al, 2006).

In the present study, out of the total 40 cases of encephalitis, $45 \%$ ( 18) were HSV (temporal lobe, insular cortex, frontal lobe involvement was seen). Reuter et al. (2007) reported that MRI abnormalities were existent in $21(87.5 \%)$ of 24 examined cases of HSVE-2 which were proven by PCR in adults. Elbers et al, (2007) conducted a study that included 16 of 322 patients with acute encephalitis that fulfilled the criteria for HSVE on MRI. Of the 16 patients, $12(75 \%)$ had HSVE detected by the CSF. In $10(83 \%)$ of the 12 patients, 
the virus detected by PCR was HSVE-1, while the virus detected for 2 (17\%) patients was HSVE-2. PCR is the gold standard for the diagnosis of encephalitis etiology.

\section{Conclusions}

Suggestive MRI findings are present in some etiologies of viral encephalitis such as Herpes simplex encephalitis, JE, enterovirus encephalitis MRI may show non-specific features of viral encephalitis such as cortical hyperintensities and cerebral edema. MRI is also useful for diagnosing alternative etiologies such as Acute disseminated encephalomyelitis, and antibodyassociated encephalopathies.

\section{References}

[1]. Beig FK, Malik A, Rizvi M, Acharya D, Khare S. Etiology and clinico-epidemiological profile of acute viral encephalitis in children of western Uttar Pradesh, India. Int J Infect Dis. 2010;14:e141-6.

[2]. Steiner I, Budka H, Chaudhuri A, Koskiniemi M, Sainio K et al. Viral encephalitis: a review of diagnostic methods and guidelines for management. Eur. J. Neurol., 2005; 12, 331 - 343.

[3]. Hills S, Dabbagh A, Jacobson J, Marfin A, Featherstone D,Hombach J, et al. Evidence and rationale for the World HealthOrganization recommended standards for Japanese encephalitis surveillance. BMC Infect Dis. 2009;9:214.

[4]. Dun V, Bale JF Jr, Zimmerman RA, Perdue Z, Bell WE. MRI in children with postinfectious disseminated encephalomyelitis. Magn Reson Imaging, 1986; 4:25-32.

[5]. Schroth G, Gawehn J, Thorn A, et al. Early diagnosis of herpes simplex encephalitis by MRI. Neurology 1987;37:179-83

[6]. Dale RC, de Sousa C, Chong WK, Cox TC, Harding B, Neville BG. Acute disseminated encephalomyelitis, multiphasic disseminated encephalomyelitis and multiple sclerosis in children. Brain, 2000; 123:2407-2422.

[7]. Marchbank ND, Howlett DC, Sallomi DF, Hughes DV. Magnetic resonance imaging is preferred in diagnosing suspected cerebral infections. BMJ, 2000; 320:187-188.

[8]. Khetsuriani N, Holman RC, Anderson LJ. Burden of encephalitis-associated hospitalizations in the United States, 1988-1997. Clin Infect Dis., 2002; 35:175-82

[9]. Granerod J, Tam CC, Crowcroft N, Davies NW, Borchert M, Thomas SL. Challenge of the unknown: a systematic review of acute encephalitis in non-outbreak situations. Neurology., 2010; 75:924-32.

[10]. Whitley RJ, Gnann JW. Viral encephalitis: familiar infections and emerging pathogens. Lancet. 2002; 359:507-13

[11]. Warrell MJ, Warrell DA. Rabies and other lyssavirus diseases. Lancet., 2004; 363:959-69.

[12]. Glaser CS, Honarmand S, Anderson LJ, et al. Beyond viruses: clinical profiles and etiologies associated with encephalitis. Clin Infect Dis 2006; 43:1565-77.

[13]. Chaudhuri A, Kennedy PG. Diagnosis and treatment of viral encephalitis. Postgrad Med J, 2002; 78:575-583.

[14]. Redington JJ, Tyler KL. Viral infections of the nervous system, 2002: update on diagnosis and treatment. Arch Neurol, 2002; 59:712-718

[15]. Lee TC, Tsai CP, Yuan CL, Wei CY, Tsao WL, Lee RJ, et al. Encephalitis in Taiwan: a prospective hospital-based study. Jpn J Infect Dis., 2003; 56:193-9

[16]. Cizman M, Jazbec J. Etiology of acute encephalitis in childhood in Slovenia. Pediatr Infect Dis J., 1993; 12:903-8

[17]. Nicolosi A, Hauser WA, Beghi E, Kurland LT. Epidemiology of central nervous system infections in Olmsted County, Minnesota, 1950-1981. J Infect Dis., 1986; 154:399-408.

[18]. Tregoning JS, Schwarze J. Respiratory viral infections in infants: causes, clinical symptoms, virology, and immunology. Clin Microbiol Rev., 2010; 23:74-98.

[19]. Cordova SP, Smith DW, Broom AK, et al. Murray Valley encephalitis in Western Australia in 2000, with evidence of southerly spread. Commun Dis Intell 2000; 24: 368-372.

[20]. Burrow JN, Whelan PI, Kilburn CJ, et al. Australian encephalitis in the Northern Territory: clinical and epidemiological features, 1987-1996. Aust N Z J Med 1998; 28: 590-596

[21]. Salih MA, El Khashab HY, Hassan HH, Kentab AY, Al Subaei SS, Zeidan RM. A Study On Herpes Simplex Encephalitis in 18 Children, Including 3 Relapses. Open Pediatr. Med. J.,2009; 3, 48-57.

[22]. Kim SS, Chang KH, Kim KW, Han MH, Park SH, Nam HW et al. Unusual acute encephalitis involving the thalamus: imaging features. Korean J Radiol., 2001; 2(2):68-74.

[23]. Smithburn KC, Kerr JA, Gatne PB. Neutralizing antibodies against certain viruses in the sera of residents of India. J Immunol., 1954; 72(4):248-257.

[24]. Chakravarty SK, Sarkar JK, Chakravarty MS, et al. The first epidemic of Japanese encephalitis studied in India - virological studies. Indian J Med Res., 1975; 63(1):77-82.

[25]. Mathur A, Chaturvedi UC, Tandon HO, et al. Japanese encephalitis epidemic in Uttar Pradesh, India during 1978. Indian J Med Res., 1982; 75:161-169.

[26]. Kumar R, Tripathi P, Singh S, Bannerji G. Clinical features in children hospitalized during the 2005 epidemic of Japanese encephalitis in Uttar Pradesh, India. Clin Infect Dis., 2006; 43(2):123-131.

[27]. Reuter MD, Manian FA, Kershaw MA, Alpert MA. Herpes Simplex Virus Type 2 Encephalitis in an Elderly Immunocompetent Male. Southern Med. J., 2007; 100, 1143-1146.

[28]. Elbers, JM, Macgregor D, Bitnun A, Richardson SE, Ford-Jones EL, Tellier R. A 12-Year Prospective Study of Childhood Herpes Simplex Encephalitis: Is There a Broader Spectrum of Disease?' Pediatrics, 119, 2007.

Table-1: Age and sex distribution of the patients

\begin{tabular}{|l|c|c|}
\hline & $\begin{array}{c}\text { No. } \\
(\mathbf{n = 4 0})\end{array}$ & \% \\
\hline Age in years & & 25.0 \\
\hline $12-20$ & 10 & 17.5 \\
\hline $21-30$ & 7 & 15.0 \\
\hline $31-40$ & 6 & 22.5 \\
\hline $41-50$ & 9 & 20.0 \\
\hline$>50$ & 8 & 1 \\
\hline
\end{tabular}




\begin{tabular}{|l|c|c|}
\hline Mean \pm SD (Range) & $37.03 \pm 21.86(12-76)$ & \\
\hline Sex & & \\
\hline Male & 22 & 55.0 \\
\hline Female & 18 & 45.0 \\
\hline
\end{tabular}

Table-3: Distribution of the patients according to clinical features $(\mathrm{N}=40)$

\begin{tabular}{|l|c|c|}
\hline \multirow{2}{*}{ Symptoms* } & \multicolumn{2}{|c|}{ Present } \\
\cline { 2 - 3 } & No. & \% \\
\hline Fever & 37 & 92.5 \\
\hline Headache & 27 & 67.5 \\
\hline Seizures & 35 & 87.5 \\
\hline Altered sensorium & 34 & 85.0 \\
\hline Neck rigidity & 28 & 70.0 \\
\hline
\end{tabular}

*Multiple responses

Table-3: MRI findings in encephalitis $(\mathrm{N}=40)$

\begin{tabular}{|l|c|c|}
\hline \multirow{2}{*}{ Particular Sites of brain involvement } & \multicolumn{2}{|c|}{ Present } \\
\cline { 2 - 3 } & No. & \% \\
\hline A. Cerebral hemisphere & & 35.0 \\
\hline Frontal lobe & 14 & 42.5 \\
\hline Temporal lobe & 17 & 17.0 \\
\hline Parietal lobe & 7 & 10.0 \\
\hline Occipital lobe & 4 & 35.0 \\
\hline Basal ganglia & 14 & 45.0 \\
\hline Thalamus & 18 & \\
\hline B. Brain stem & & 32.5 \\
\hline Midbrain & 13 & 27.5 \\
\hline Pons & 11 & 27.5 \\
\hline Medulla & 11 & 30.0 \\
\hline C. Cerebellum. & 12 & \\
\hline
\end{tabular}

*Multiple responses

Table-4: Etiology of encephalitis cases $(\mathrm{N}=40)$

\begin{tabular}{|l|c|c|}
\hline Etiology of encephalitis & $\begin{array}{c}\text { No. } \\
(\mathbf{n = 4 0 )}\end{array}$ & \% \\
\hline Herpes simplex virus encephalitis & 18 & 45.0 \\
\hline Japanese Encephalitis & 22 & 55.0 \\
\hline
\end{tabular}

